\title{
Conceptualising Capabilities and Dimensions of Advantage as Needs*
}

\author{
Benjamin Fardell
}

Published (2020) in the Journal of Human Development and Capabilities.

Final accepted manuscript. Do not cite this version; the published version is available on request, or at https://www.tandfonline.com/eprint/2GIUIQIHACKYIKZBRNUX/full?target=10.1080/19452829.2020.1777952.

\begin{abstract}
Amartya Sen's critique of the concept of need and his case for the superiority of capability as a measure of advantage have been highly influential. However, Sen perpetuates a caricature. Needs are not necessarily mere instrumental resource requirements for the achievement of ends; the valuable ends of people's lives can themselves be needs, and people can need both freedoms and functionings. Indeed, this idea is already present in basic needs theory. Moreover, official disavowals notwithstanding, expansive notions of need are implicitly present in certain important theories of capabilities and other advantages. Objections to need can be undermined in part by showing how this is the case. Aversion to need is unfortunate, because the concept offers powerful theoretical resources that could be better exploited if negative preconceptions are overcome and need is explicitly embraced. However, this proposal is friendly. It is not that need should replace, but that it can augment, other concepts. Drawing on need may assist with: selecting important capabilities or dimensions of advantage; marking a distinction of seriousness between these and relatively trivial advantages (and buttressing claims to the ethical or political priority of the former); explaining the incommensurability/non-substitutability of certain capabilities and dimensions of advantage, and; defining notions of sufficiency.
\end{abstract}

\section{Introduction}

Although the Basic Needs Approach to development (BNA) was a path-breaking precursor to many contemporary multidimensional approaches to evaluating (dis)advantage-not least the Capability Approach (CA) — today many theorists and practitioners in these areas are sceptical about the relative usefulness and attractiveness of the concept of need. In Amartya Sen's influential critique, needs are exclusively instrumental (i.e., mere means), material requirements that are insensitive to interpersonal variation. He argues that in development a focus on needs should be superseded by a focus on capabilities, which by contrast (for him) refer to people's ends, their well-being and "agency", what they are able to do with resources. He claims further that whereas aiming to meet needs treats beneficiaries as passive recipients, promoting capabilities empowers them to freely act themselves (Sen 1984, 513-4). Needs may also seem an overly limited focus for evaluating advantage over and above mere subsistence, and meeting

\footnotetext{
* I am grateful to James Wilson and Ingrid Robeyns for discussion and comments on earlier versions of these ideas, and to an anonymous associate editor and anonymous reviewer for their recommendations.
} 
them as an unattractively minimal socio-political objective (Goodin 1984, 624). However, this paper argues that it is a mistake to think that needs are necessarily instrumental, minimal, and inflexible. A person's needs can also include non-minimal, non-instrumentally valuable ends and freedoms; moreover, these may be particular to that particular person. Furthermore, that needs may have these features is demonstrated already in the unacknowledged use of the concept by those officially resistant to it. Other authors have also noted, in passing, that capability theorists rely on the concept of need more heavily than they acknowledge (Brock 2009; Boulanger 2011), and have offered penetrating rebuttals of charges against the Basic Needs Approach in particular (Reader 2006). However, here I mount a more general and detailed defence of the concept itself, and make clearer the ways its detractors in fact implicitly rely on it. I argue that some higher, finally valuable goods (as represented by the dimensions, capabilities, and functionings in some multidimensional approaches to evaluating (dis)advantage) already formally represent, and are thus apt to be explicitly described as, needs.

Although this proposal to some extent subverts needs-critics' own positions, it is intended as friendly. The argument is not at all that alternative concepts ought to supplant capabilities and other multidimensional constructs. Like other scholars proposing that capability theorists could benefit from taking a fresh look at the concept of need (O’Neill 2011; Robeyns 2017, 174-9), I argue that doing so could complement existing approaches. By making explicit and embracing already existing and potential connections with need, capabilities and other pluralist theorists can appropriate, for their own purposes, the powerful theoretical resources that need offers and more generic value concepts lack. I propose several specific ways drawing on the concept of need could be helpful. For the most part I focus on how it can inform the evaluation of well-being in particular, but there is also potential for it to play a conceptual role in other notions of advantage.

The following section focuses on the relations between capabilities and needs, beginning by deflecting certain criticisms of the BNA. To the extent that many other multidimensional approaches draw inspiration and normative rationale from the CA, often even constituting operationalisations of it (World Bank 2017, 135; cf. Alkire et al. 2015), these have wide relevance. Section 3 shows how needs 
are also implicitly operative in pluralist conceptions of well-being beyond the CA, and further demonstrates the flexibility needs may possess. Section 4 concludes by summarising the advantages explicitly adopting the concept of need offers.

\section{Capabilities and Needs}

I decompose Sen's complaint against needs into the following claims:

(i) Need in the context of well-being, and related evaluations of "quality of life", is an exclusively instrumental relation that defines a relatively minimal level of attainment.

(ii) A focus on needs cannot provide a sufficient role for freedom and human activity.

(iii) Needs, defining material preconditions for human beings in general, are insensitive to differences in people's abilities to convert resources into pursuing their ends.

I rebut them in order; (i) and (ii) in this section, and (iii) in the section following.

The thought behind claim (i) is that need is a notion fundamentally ill-suited to describing final human goods. 'Needs' may be capable of describing preconditions for these, but not valuable functionings and capabilities themselves. To disprove this claim it is enough to examine the real nature of the BNA, rather than how Sen and others have inaccurately characterised it. The BNA appears in fact to have been home to at least two different understandings of 'basic needs'. Its main proponents admit that the needs aimed at in practice were indeed almost entirely instrumental and relatively minimal, and thus vulnerable to Sen's critique. The BNA was proposed as part of an urgent response to dire poverty in low-income countries that the then-prevailing GNP-growth development paradigm was failing to address, and from the start many of its theoretical priorities were pragmatic and technical, focused on application and delivery of material assets (Stewart 2006, 14; Streeten 1984, 976). For its leading theorists, however, 'basic' does not mean 'minimal', but, it appears, 'fundamental' in the sense of 'essential'-essential to living a distinctively human life. Basic needs, for them, encompass all of the necessary conditions for living a "full life", where this includes "non-material" needs that are ends as well as material needs that are instrumental prerequisites for ends (Stewart 1985, 2-5; Streeten 1984, 974). As I interpret it, this full-life notion is possible because instrumental necessity is not the only, nor even the most significant, form of necessity in the domain of values. Another form is constitutive necessity, that 
something is a necessary part of some whole. Something is necessary in this sense if it, along with all other necessary parts of some whole, is required in order for that whole to exist. An account may hold that there are certain integral elements that no good life can do without, that is, which are constitutively necessary for well-being. This is a claim that there are things people need that are of final value: necessary, but not pursued for any further end beyond the good life of which they are part. BNA theorists freely admit that practice imperfectly reflected theory, and that its conceptual foundations are underdeveloped relative to the CA (Stewart 2006, 18; Streeten 1984, 976). It is nevertheless fairly clear that, as BNA theorist Frances Stewart writes,

In its reductionist form, the capability approach is very similar to the BNA: the objective of enhancing what people can be or do (a person's capabilities) is virtually identical with the full-life objective of the BNA; and in order to achieve this for the most deprived, a subset of basic capabilities has been identified. (Stewart 2006, 18) ${ }^{1}$

We see, then, that the "basic needs" of the BNA are not fully determinate, but rather open to different interpretations. The full-life interpretation is far from minimal, and embraces the final ends of life as well as the means to those.

Now consider the charge that conceptualising well-being, quality of life, or similar notions in terms of needs will leave too little room for freedom and activity. Sen's capability theory emphasises freedom and activity in two ways. One is how, as on all capability theories, freedom is built into the notion of a capability itself, which is a real ability to function in some way: to have a capability is to have the freedom to function or not function in that way. ${ }^{2}$ The second way in which freedom is a part of Sen's capability theory is that a person's capabilities include not only freedoms to function that affect their well-being, but also what he calls their "agency goals" - that is, the goals people have to act on the world beyond themselves, deriving from their values more broadly (Sen, 2009, 287-9; Sen 1993, 35). For Sen, a person's well-being concerns only their personal state narrowly conceived, whereas their quality of life consists additionally in their achievement and/or capability to pursue their agency goals. Capabilities are able thus to exceed needs, on Sen's view, because needs (a) describe only things a person needs to possess, rather than what they do and are able to do with them, and (b) are limited to a person's well-being, not their "agency" (Sen 2009, 251-2). However, although it is possible to define a class of needs this way, it 
is crucial to notice that, more generally, needs do not always or even usually refer to baving things. In the living of their lives, people also need to do many things (possibly also to be certain kinds of person) (Wiggins 2005, 32; Max-Neef et al. 1989) —and these are not in general things anyone else can do on their behalf. If some active pursuits by the person themselves are necessary components of their living a full life-which Sen's own discussion of the importance of "agency" suggests is correct—-then (by definition of "full life") those pursuits are among a person's needs. Thus contrary to Sen, conceptualising development in terms of needs need not mean treating people only as patients. On a needs account, too, development requires not only ensuring people have certain goods, but creating space in which they can do so; people need that space. This possibility is again evident in the BNA's actual conceptualisation. As Paul Streeten wrote, "The objective of a basic needs approach is to provide opportunities for the full development for the individual" (Streeten 1979, 136, my italics). It is true that certain formulations of the BNA are open to criticism concerning the way they seek to incorporate concern for freedom-for example, by including 'autonomy' as a separate dimension alongside other needs—where the criticism is that freedom should be a factor in each individual attainment as per the CA (Alkire 2002, 170). This may be a legitimate criticism of the design of specific BNA proposals. At issue for present purposes, however, is not whether any particular account is adequately developed either as a conceptualisation of needs or an approach to development. There is no conceptual requirement for needs to be formulated along the lines of any extant proposal (cf. Reader 2006, 345). The simple point here is that the concept of need is flexible. It can allow that besides needing to have, people can also need to do certain things, and it can even allow that people need the freedom to do certain things, that is, to have certain capabilities.

Some proponents of capabilities do already recognise, implicitly and explicitly to varying degrees, that some capabilities are needs_-or, equivalently, that some needs are capabilities_-, however little acknowledged this appears beyond the following statements. At least in this early characterisation, and notwithstanding his objections to the BNA, Sen explained that the concept of capability is an “interpretation of needs", and "a natural extension of [John] Rawls's concern with primary goods" (Sen 1980, 218). (Where Rawls in turn held that primary goods are "citizens' needs", those things people "in 
general need as citizens in a just society" (Rawls 1982, 172-3, 183). ${ }^{4}$ ) Sabina Alkire has similarly characterised the CA as "framing needs in terms of human capabilities" (Alkire 2005, 248; cf. O’Neill 2011,28). This is clearest where, parallel to basic needs (minimally construed), capability theorists have developed a notion of basic capabilities for the purposes of poverty evaluation. In that context, "“basic capabilities' refers to the real opportunity to avoid poverty or to meet or exceed a threshold of wellbeing” (Robeyns 2017, 95). Alkire in particular defines these not in terms of just any threshold but as retaining a tight link with basic needs. For her a basic capability is "a capability to enjoy a functioning that is defined at a general level and refers to a basic need, in other words a capability to meet a basic need" (Alkire 2002, 163). Yet as a matter of logic there is a tighter link than even this. If having some set of basic capabilities defines a threshold of what is necessary to avoid poverty (where these are already capabilities to meet basic needs), then it follows that these are capabilities that in the sense of "basic" here are things a person needs. In another place Alkire explicitly asserts this, albeit avoiding using the term 'need': they are "capabilities which are indispensable to human flourishing” (Alkire 2002, 166). Clearly, by convention in this domain the term 'basic needs' is reserved for functionings that are basic (in the minimal sense). But if both basic capabilities and functionings are needs, then it would be natural to redefine a person's basic needs as comprising both basic capabilities and basic functionings. We cannot easily wind back entrenched uses of terms, but if it were possible this proposal would more clearly regiment these concepts, also bringing into the open the legitimacy of using 'need' to refer to things other than what are conventionally designated basic needs.

Even more than this, as we saw in the case of the BNA as actually theorised by its proponents, needs can extend far beyond minimal attainments to include ends. If certain non-minimal capabilities are among the constitutively necessary elements of a good human life, then they eo ipso count as things a person needs in that sense. There is a point in a discussion of basic needs at which Sen does seem to acknowledge that basic needs might not yet be so fully specified as to exclude capabilities and valuable ends—even though by the end of that discussion he seems to have made his mind up that basic needs are only instrumental commodity requirements. He writes there that if finally valuable functionings and capabilities were included, a basic needs theory would look rather a lot like a capabilities theory (Sen 
1987, 25). That seems right. By the same token, however, it would also mean that that kind of capabilities theory already looks rather a lot like a theory of needs_-an enriched account, compared to basic needs conceived in minimal, exclusively commodity terms, but a needs theory all the same. So we should give up the common prejudice that needs = minimally construed basic needs. Concepts of need (and even basic need) are, and should be recognised to be, more flexible than appears commonly supposed. Moreover, if we choose to reserve 'basic' for 'minimal' (unlike important BNA theorists, as we have seen), we should allow that people can have needs that are very much non-basic. ${ }^{5}$

None of this diminishes the concept of capability in any way. ${ }^{6}$ It is a crucial insight of capability theory that real opportunities for attaining certain things can be important in their own right, in addition to actually securing those things. The concept of need does not supply this feature. Capability and need are discrete concepts, and their extensions only partially overlap. The point here is only that that intersection does exist and is important to recognise. Many capabilities are not needs, and many needs are not capabilities, but, whether they are designated so or not, some attainments constitute both capabilities and needs-necessary capabilities. In the context of well-being evaluation, they are those capabilities the possession of which is constitutively necessary for a good life. To call them needs is not to say that they are 'just' needs, since the concept of capability importantly distinguishes them from any other attainments also constitutively necessary for a person's good life that are only functionings or otherwise not capabilities. At the same, presumably there are other capabilities lying outside of the overlap: capabilities that improve well-being, for instance, but which a person could lack and still have a good life. ${ }^{7}$ Consider pure pleasure, if there is such a thing. It might always be good for the person to have greater capability for pure pleasure, yet in order to have a good life they might only need such capability to some sufficient extent. Capabilities for enhanced pleasure beyond that threshold might be beneficial, but not constitute needs. I discuss possibly unnecessary capabilities and well-being components further in section 3.

Martha Nussbaum's theory of justice is a clear example of a theory that endorses the constitutive necessity for a good life of the capabilities it identifies, if not in so many words, thereby implicitly (also) constituting a theory of needs. Nussbaum lists ten "central capabilities" that "are important for each 
and every citizen, in each and every nation, and each is to be treated as an end" (Nussbaum 2000, 7880, 6). They are "certain functionings [that] are particularly central in human life, in the sense that their presence or absence is typically understood to be a mark of the presence or absence of human life" (ibid., 71-2). More specifically, they are such that "beneath a certain level of capability, in each area, a person has not been enabled to live in a truly human way"- "a life that is worthy of the dignity of the human being" (ibid., 74, 5). Nussbaum claims that every person has a right to these which "may not be infringed upon to pursue other types of social advantage" (ibid., 14). With Bernard Williams she agrees that which rights people have is determined by which features of well-being are especially important (ibid., 97-8; Williams 1987, 100). Rights are an appropriate structure for protecting central capabilities because the latter are incommensurable, in the sense of non-substitutable: "each and every one of a plurality of [these] distinct goods is of central importance"; they are "separate" in a sense that entails that "[w]e cannot satisfy the need for one of them by giving a larger amount of another one" (Nussbaum 2000, 81). Given all this, the question arises: why stop short of saying explicitly that these are not only "important" and "central", but necessary? Indeed, if Nussbaum is right that some attainment of every capability/functioning is required in order to live a fully human life, then by the logic of 'requirement' her central capabilities constitute needs, whether she prefers to speak in those terms or not. That each and every central capability is necessary would furthermore be explanatory of why having one cannot generally serve as well as another. Necessity is just the abstract form of requirement that such non-equivalence logically entails: to say that nothing else will do as well as $\mathrm{X}$ just is to say that $\mathrm{X}$ is necessary; and if $\mathrm{X}$ is necessary, then nothing else will do as well, there is no substitute for it.

Marco Grix and Philip McKibbin have suggested that pluralist theories of well-being in general might indeed usefully be characterised as theories of which elements are needed for a good, distinctively human life. One advantage they see in this proposal is that it would meet the charge that the items on a list of plural well-being elements are arbitrary. That the items were all necessary for living well would explain which should be on the list (Grix and McKibbin 2015, 302). In Nussbaum's case, central capabilities' necessity would explain why people have a right specifically to those capabilities and not others that are not necessary and as such relatively trivial. An exemplary case of actually adopting this 
approach, implicitly nevertheless, is Jonathan Wolff and Avner de-Shalit's study of disadvantage. Preferring albeit to refer to functionings rather than capabilities, Wolff and de-Shalit adapt Nussbaum's list (with two additions), and follow her in considering each functioning to be required for flourishing (Wolff and de-Shalit 2007, 41)—though, again, abstaining from explicitly employing the concept of need. With the intention of confirming their list they conducted interviews with a selected group of people with intimate experience of disadvantage (some suffering it, others working in welfare service provision and social policy), and in these we see them testing their list against precisely this criterion. Their interviewees' "first task was to name what they thought [are] the basic categories for essential functionings" (ibid., 188, my italics). One interviewee is even asked, "What do you think are the main necessities [for] one's well-being?” (ibid., 61n). So it is unclear why they are surprised when they remark, "It is interesting then that not everyone felt comfortable discussing categories of functionings, and that some interviewees settled more easily into 'basic need' talk" (ibid., 106). Both Wolff and de-Shalit and their interviewees continually turn to the language of need. Mostly, this language passes unacknowledged, just slipping in such as when Wolff and de-Shalit write that "some interviewees formulated a distinction between what is needed for a barely acceptable life, and what is needed for a good life" (ibid., 51). Where interviewees do not believe that some functioning on the proposed list is important, they often frame it as something they do not need, or explain that a life could be good without it (e.g., ibid., 53). Wolff and de-Shalit do entertain the idea that belonging is a need, as per Abraham Maslow's view that it is a psychological prerequisite for a feeling of self-worth, and they seem to endorse its spirit because they move on without rejecting it (ibid., 54; Maslow 1943). There is also a general emphasis on the interdependence of functionings, much of which concerns what is jointly necessary for which other things. For a last, especially revealing example:

What became clear in our initial discussions, and, as we shall see, even more so in the interviews, is that while it is true that in order to flourish as an individual one needs to have one's self-referring functionings developed and sustained — one needs to see that one gets things for oneself - it is equally true that one also needs to be a person who has feelings for others, and is able to express them in appropriate ways. Being able to care for others is part of being a person, at least under normal conditions, and therefore part of one's well-being. (Wolff and de-Shalit 2007, 46) 
Notice the appeal to constitutive necessity here. We can call these mere well-being functionings if Wolff and de-Shalit prefer, but if they are things that are necessary for a good life then they are eo ipso needs and we should not hesitate to designate theories of this kind in those terms.

\section{Must Every Dimension Be a Need?}

Unlike Nussbaum and Wolff and de-Shalit, Alkire, together with theorists such as James Griffin and Mozzafar Qizilbash, explicitly deny that every dimension they identify must be present to some extent in a person's life. Since, as I have suggested, that is a plausible condition a theory must meet in order to count as a needs theory, this strongly suggests that for all I have said so far their dimensions are not needs. Griffin and Qizilbash (who proposes applying Griffin's account to development) are also critical of basic needs, and furthermore view their plural dimensions (of "prudential value") as reducible to a single scale (Qizilbash 1996; Qizilbash 1998; Griffin 1986, ch. 3, 90), so it is especially unobvious in their cases. However, in this section I want to disturb this appearance by pointing out how their disavowals of needs are belied by other aspects of their own accounts. In the course of doing so, I show that although plural dimensions are not necessarily needs, it is harder to avoid making them count as such than it might seem, and that allowing them to count as needs even has advantages on these theorists' own terms.

\subsection{Different People, Different Needs}

Given how closely Qizilbash follows Griffin I treat the two together. On the face of it, their dimensions do not behave at all like needs. Griffin's list comprises a "profile of components of a valuable life", things which would make anyone's life go better if they had them, and these can ostensibly be traded off by how much "worth to one's life" they add (Griffin 1986, 114). Nevertheless, Griffin writes things like this:

Pleasure, accomplishment, autonomy, loving relationships are all valuable. A life with only one or two of them, even in large quantities, would not be the best life. (ibid., 70)

Although Griffin most often describes these "prudential values" only as "important", this here sounds very much like at least some of them are indispensable. Qizilbash also usually writes in terms of generic value, but he also makes revealing slips, such as when he refers to one value ("aspiration") as being "a 
necessary condition for the pursuit of the good", without which one is "deprived". He also argues that "we do not need a great deal of understanding: it is a basic understanding of ourselves and our world that makes our lives go better" (Qizilbash 1998, 68, 65). Presumably the implication is not that we do not need any understanding, but that we do need some (though only to a relatively minor extent). Among certain minor departures from Griffin, Qizilbash also includes basic needs on his list, although he makes much of renaming them "basic values"- for the reason that they are not necessarily to be prioritised over less basic values, which he takes to be a feature of basic needs (ibid., 66; cf. Griffin 1986, 45).

Griffin and Qizilbash's core motivation for denying that all dimensions are necessary is to allow for interpersonal variability. They object to basic needs and objective-list theories of well-being that are insensitive to personal differences. On the one hand, Griffin's and Qizilbash's prudential values are universal and objective, adding value to anyone's life if they have them, whatever their beliefs and attitudes may be. But on the other, how much worth they add varies from person to person. Since values can come into conflict, this also means

\footnotetext{
that there may be very special persons for whom any value on the list (say, accomplishment), though valuable for them as for everybody, conflicts enough with another value (say, freedom from anxiety) for it not, all things considered, to be valuable for them to have. (Griffin 1986, 33)
}

Qizilbash similarly allows that some person might give up everything besides "minimal nourishment, in order to achieve self-discipline", and that "that also could be a prudentially good life" (Qizilbash 1998, 67n). Even other theorists who endorse dimensional incommensurability, rejecting apparent cross-dimensional substitutability, allowed by Griffin's and Qizilbash's accounts, might also reject the idea that each dimension is a need on a similar basis. Non-substitutability across dimensions follows from necessity, it might be held, but perhaps the reverse does not hold: dimensions might be severally 'important', adding value to people's lives in ways that are somehow fundamentally essentially different, yet without each being a necessary part of anyone's. Alkire's account might appear to be an example of this position, as, similarly to Griffin's and Qizilbash's view in this respect, it “allows for the possibility that individuals may be 'flourishing' even if one or more dimensions is not valued or present very much in their lives and commitments" (Alkire 2002, 53, 165). 
We should share Griffin's, Qizilbash's, and Alkire's concern to allow for variation between persons. Still, it leads us astray if we suppose that variation is essentially incompatible with need. Griffin writes,

All needs accounts rest on a distinction between, on the one hand, things that we aim at simply as normal human beings rather than as the particular human beings we are, things that are both necessary to and sufficient for a recognizably human existence, and, on the other hand, things that, as the individuals we are, we choose to go for. (Griffin 1986, 53)

Rejecting the insensitivity of material basic needs to individual differences is also a core motivation for adopting the capabilities approach. Besides ignoring the variety in people's ends, a focus on needs in terms of commodities risks ignoring differences in how people are able to use them and convert them into valuable functionings and capabilities (Robeyns 2017, 113-4). This is Sen's complaint (iii), as listed at the start of section 2 . However, it is simply not true that a needs theory must propose that one size fits all. We can easily allow that different people need different things-in terms of resources required to achieve given ends, yes, but also that they have different ends they need to pursue. This seems a natural thing to say, if we are not in the grip of the preconception that needs $=$ minimal basic needs. The necessary constituents of a good life most plausibly vary across persons. In fact, this is illustrated by Griffin's own account of personal values that ostensibly excludes needs. For Griffin, although there is wide variation between people, he claims that for each person there is a mix of prudential values, different values realised to different extents, that is best or most suited to them (Griffin 1986, 60). The good life for Griffin's person especially prone to anxiety does not require accomplishment. It follows that it is not a need for them. Yet although it is not a need for them, Griffin is implicitly claiming that there are other things that they do need in order to live the life that best suits them. He describes accomplishment as "giving weight and substance to our lives", alternatively "avoiding wasting our lives" (ibid., 30). For other persons, then, if the good life suited to them does include accomplishment, this sounds like they had certainly better have it. Almost by definition, avoiding wasting it is necessary for a good life, and if, for some, this requires accomplishment, then that is necessary for them to have good lives. Those things are needs for them—in a personal sense of needs particular to particular persons.

Crucially: all this can be so even while lists of needs constructed for public purposes cannot be entirely sensitive to variation in the specific needs entailed by particular persons' particular good, just as 
lists of capabilities used for public purposes cannot be entirely sensitive to which capabilities are valuable to different people. Giving up the prejudice allows that: (a) 'not every person needs all of the items on a list' is compatible with (b) 'those items designate the kinds of things that those people (in the group under evaluation) generally need'. Griffin, Qizilbash, and Alkire appear, in effect, to be proposing generalisations about needs of this kind.

I elaborate further on the relevance of generalisation in the following subsection, but before getting to that, notice how, although Griffin might be unhappy about this proposal to implicate needs in his own account, there is a way they could be useful for him. For him, the different mixes of prudential goods appropriate to different people partly depend on their differing capacities and skills (ibid., 59). But they do not only depend on these, nor only on people's mere likings or tastes for different things. They appear to depend on something more fundamental to themselves. He draws a distinction between, on the one hand, objects of a person's desires that are "capricious or accidental or arbitrary", and, on the other hand, a person's "non-universal, non-neutral values", the kinds of things that they might have as a life goal or central commitment. About such non-universal values, he writes, "And it is odd to think even that we choose them; generally they choose us, by being the sorts of values that we only have to perceive clearly to adopt as goals" (ibid., 54). It seems, then, that a person can find it somehow crucial or irresistible (essential?) to their life that they are able to pursue some goal they have. The useful role the concept of need can play here is in distinguishing the serious values constituting the good of some person's life from the satisfaction of their trivial desires: they are those serious values constitutively necessary for their life going well. This comes without any implication that everyone's serious values, their needs, are the same.

There is another reason well-being pluralists like Griffin and Qizilbash might resist considering their dimensions needs. I mentioned in section 2 the Grix-McKibbin condition for whether an item should be on a list of goods contributing to well-being, and I argued that following it seems to describe some of what the pluralists I discussed earlier are up to. Yet the procedure seems to presuppose operating with such a notion as a 'good life' or 'full life' sans phrase, that is, without needing to specify how good or full it is - simply opposed to a life that fails to be good or full, period. It suggests the idea of sufficiency, 
that people must have at least a certain extent of attainment along each dimension in order to have a sufficiently good life, where otherwise we cannot say without qualification that they have a good life or not. The concept of need is indeed well-placed to support theories employing notions of sufficiency (e.g., Nielsen and Axelsen 2016), offering a definition of sufficiency as (being capable of) having, doing, and being everything the person needs. But this would ignore a different selection method some pluralist philosophers favour. This is to take two lives that are equal in every possible way and consider simply whether adding attainments of some good to one make it better than the other (e.g., Fletcher 2013, 218; Hooker 2015, 19). Indeed, many well-being pluralists do seem to think of their dimensions as goods that a person can simply have more or less of, like silos that they can fill to greater or lesser extents. This fails to contradict the claim that Griffin and Qizilbash implicate needs, however: it could still be that a person needs to have some threshold level of each of these goods in order to have an unqualifiedly good life. Needs may thus coexist with silos. (A feature of such a view could be that, while having enough of one dimension may not be substitutable by having more of another of which one already has enough, there is substitutability across dimensions above this constraint.) I believe that this is the correct interpretation of Griffin's and Qizilbash's implicit positions. Their prudential goods are like silos, but there is strong evidence that they also believe filling each at least to some threshold level is constitutively necessary for having the good life suited to them in particular.

\subsection{Flexible Sets and Needs}

Alkire and some other capability theorists follow Sen in rejecting the notion that one fixed list should be chosen (Alkire 2002, 29; Sen 1993, 47; Sen 2004, 80). This stands in contrast with Nussbaum's intention that her list be universally applicable, and her claim that people in every society have a right to every capability on it. Although Nussbaum is concerned to account for cross-cultural variation, the way she does so is by appeal to "multiple realizability": she claims that although the same ten capabilities are central everywhere and to everyone, they are concretely specified in different culturally specific forms (Nussbaum 2000, 77). In the contrasting approach of Alkire and others closer to Sen in this respect, the appropriate capability set need not be derived from an all-purpose template of capabilities described at a very high level of generality. Indeed, although Nussbaum's central capabilities might be suited to 
specifying constitutional principles, which she indeed takes as her main target, their generality and fixity make them unsuited to other purposes, such as well-being or poverty evaluation (Alkire 2002, 38). Instead, for Alkire and Sen, the selection of capabilities may be based directly on features specific to the context of measurement, influenced also by the purposes of the evaluation and other pragmatic considerations. I leave aside which methods should be used for selecting capabilities, whether those be democratic deliberation (Anderson 1999, 2003; Crocker 2008), participatory processes (Alkire 2002; Frediani 2007), the inquiry of a philosopher-investigator (Claasen 2011), or other means. What is important here is that however that is done there is a process of generalisation over personal differences to some extent—-some single set of capabilities is selected in order to evaluate and track changes in the target group as a whole-but where this is something undertaken differently for the purposes of each application (Alkire 2016, 619). Indeed, Alkire argues that what she terms "general functionings" can be identified, which are important general types of valuable functionings that are in a sense multiply realisable, but not necessarily common to all of humanity, potentially only locally, upon which interpersonal agreement within the group can be reached to serve as a standard. For example, as Sen writes, "there may be more agreement on the need to be entertained, or to have the capability to take part in the life of the community, than on the form that entertainment must take or on the particular way the life of the community may be shared" (Sen 1995, 109; Alkire 2002, 31, 53). Unlike the Nussbaum-style approach, in this way the set is chosen from the bottom up, as it were, a generalisation made for a specific purpose, rather than beginning with universals and then interpreting particulars as instances of those from the top down. Which capabilities are valuable may thus be particular to specific individuals and groups in a way unlike accounts of universal lists such as Nussbaum's central capabilities and some accounts of basic needs. Crucially, this disconnection of particular selected sets from any universal set overarching all contexts means that not every capability that is important to a given person must stand as a capability that is essentially common to all of humanity or even to all members of the group only differently manifested. That is to say, and as I quoted Alkire above, even given a set of capabilities selected for a particular evaluative application, not every person may need to possess every one of those capabilities in order to have a good life (Alkire 2002, 53,165). And again, this is precisely why such a set 
could list the kinds of things that some but not all members of a group under evaluation need. Some of a person's needs may be particular to themselves and other people similar to themselves, but not sufficiently widely shared to be included in a set of functionings and/or capabilities serving as a common basis for certain kinds of evaluation and decision-making taken by or for the wider group of which they are members. But they are still in a particular sense that person's needs.

To summarise, there is nothing preventing the foregoing approach I have sketched from identifying sets of functionings and/or capabilities that: (a) are highly particular to a target group, not based on universals; (b) comprise functionings and/or capabilities we designate as needs because they are generally needs for members of that group (and use them to evaluate and track the extent of need-satisfaction in the group as a whole), but which; (c) are not needs for all members of that group.

\section{Conclusion}

Despite some misunderstandings, needs do not necessarily possess the negative features commonly attributed to them. They can represent ends as well as means; that is, non-minimal and necessary constituents of well-being or some other state of advantage. Needs can be active, not only to have things, but to do and be things; crucially people can also need to have certain capabilities. Like capabilities valuable to some persons but not others, needs need not be universal preconditions for or aspects of the life of human beings as such; they can be personal. However, this paper has not argued that advantage and well-being should be conceptualised in terms of needs instead of other concepts, nor indeed defended any specific construct of advantage or well-being at all. Its aim has been to show how the concept of need is not necessarily opposed to, but rather can angment other approaches. Unified accounts are possible which recognise that some attainments theorised even roughly in existing ways are not merely good or beneficial for a person to have, but also needed. Indeed, as I have shown, prominent capabilities and multidimensional well-being theorists already implicitly employ concepts of need that are expansive in one or more of the respects I mentioned. Explicitly drawing upon the resources need offers can strengthen accounts of well-being and (dis)advantage, including capability theories, in a number of ways: 
- Need distinguishes serious from relatively trivial values. If what are at stake in some context are 'especially valuable' or 'central' things, critical to certain people's well-being, without which they could not unqualifiedly flourish, then those are things those people need.

- Employing need might aid the selection of dimensions, functionings, or capabilities—identifying which to regard most important and to focus on in some application.

- Understanding certain dimensions, functionings, or capabilities as needs vindicates any incommensurability attributed to them that ostensibly blocks their being traded off against other goods, which is otherwise difficult to convincingly justify. This connection is strongly suggested by the logical relation between need and non-substitutability.

- There is also a logical relation between necessity and sufficiency-sufficiency is achieved when all necessary conditions are fulfilled. A sufficient state of well-being or advantage for a person would be having, doing, being, and/or being capable of (having/doing/being) everything they need.

Together, these features of needs promise a further contribution not yet mentioned. As Alkire, following David Wiggins (1998, 5-6), acknowledges, the rhetorical force 'need' possesses is a powerful advantage that the terms 'functioning' and 'capability' lack (Alkire 2002, 162-3). However, this need not be conceded whenever capabilities, functionings, or dimensional attainments otherwise-conceived are at the same time needs. In many cases it can be forcefully and truly asserted that a person needs some functioning or capability (and that one in particular), even while it is a non-minimal contributor to their wellbeing or advantage and/or particular to that person.

\section{Notes}

${ }^{1}$ Compare Sabina Alkire's conclusion that "[i]t would seem that the basic needs approach, while perhaps lacking an adequate philosophical framework, did have all of the elements of the capabilities approach in view (this is not to say that all socalled 'basic needs' programmes exemplified these elements)” (Alkire 2002, 173).

2 Ingrid Robeyns notes that in Sen's earlier work the term "capability" designates the entire set of functionings which are open to a person to choose, some actual, the others possible. The notion of a "capability" as a particular freedom to function in one particular way or narrow set of ways (and of a person hence having a range of "capabilities") comes from other 
authors, and Sen only later partly adopted it (Robeyns 2017, 91-2). I follow the later, now-standard usage, not the original sense, allowing for plural "capabilities".

${ }^{3}$ In that text Sen uses the term "basic capability". As Robeyns explains, at that point basic capability referred to what he later simply called "capability", reserving basic capability for something different, roughly capability corresponding to a threshold level of deprivation (Robeyns 2017, 94; cf. Sen 1995, 45n).

${ }^{4}$ Note, however, Rawls' emphasis that primary goods are a device used purely in the description of the basic structure of a just society, not a metric of well-being or advantage in any other application.

${ }^{5}$ Some philosophers argue that (non-instrumental) needs are exclusively minimal, universal (at least within some society), and essentially connected to political obligation (Braybrooke 1987; Miller 1999; Thomson 1987; Wiggins 1998). Others argue that, in private-morality contexts alternatively, needs may be particular to individuals, although still relatively minimal (Brock and Reader 2002; Reader and Brock 2004). Anscombe (1958) and Grix and McKibbin (2015) notably allow that a person's needs may be more expansive — connected with human flourishing — and not necessarily moralised. My proposal that needs can be both expansive and personal is relatively uncommon, but compare Miller (1979) and Raz (1986). I discuss the philosophical literature on needs elsewhere, as doing so here would take this paper too far afield.

${ }^{6}$ I thank an associate editor for recommending I reemphasise this, and for pressing me to explain more precisely why need supplements capability without replacing it.

${ }^{7}$ In Sen's framework, again, the relevant notion of 'good life' in some context may be either well-being or quality of life.

\section{References}

Alkire, Sabina. 2002. Valuing Freedoms: Sen's Capability Approach and Poverty Reduction. Oxford: Oxford University Press. 2005. 'Needs and Capabilities'. The Philosophy of Need, Royal Institute of Philosophy Supplement 57: 229-251.

2016. 'The Capability Approach and Well-Being Measurement for Public Policy'. In The Oxford Handbook of WellBeing and Public Policy, edited by Matthew Adler and Marc Fleurbaey. Oxford: Oxford University Press.

Alkire, Sabina, James E. Foster, Suman Seth, Maria Emma Santos, José Manuel Roche, and Paola Ballon. 2015. Multidimensional Poverty Measurement and Analysis. Oxford: Oxford University Press.

Anderson, Elizabeth S. 1999. 'What Is the Point of Equality?’ Ethics 109: 287-337.

_. 2003. 'Sen, Ethics, and Democracy'. Feminist Economics 9: 239-261.

Anscombe, G. E. M. 1958. 'Modern Moral Philosophy'. Philosophy 33: 1-19.

Boulanger, Paul-Marie. 2011. 'The Life-Chances Concept: A Sociological Perspective in Equity and Sustainable Development'. In Sustainable Development: Capabilities, Needs, and Well-Being, edited by Felix Rauschmayer, Ines Omann, and Johannes Frühmann, 83-104. Abingdon: Routledge.

Claassen, Rutger. 2011. 'Making Capability Lists: Philosophy versus Democracy'. Political Studies 59: 491-508.

Braybrooke, David. 1987. Meeting Needs. Princeton, NJ: Princeton University Press.

Brock, Gillian. 2009. Global Justice: A Cosmopolitan Account. Oxford: Oxford University Press.

Brock, Gillian, and Soran Reader. 2002. 'Needs-Centered Ethical Theory'. The Journal of V alue Inquiry 36: 425-434.

Crocker, David A. 2008. Ethics of Global Development: Agency, Capability, and Deliberative Democracy. Cambridge: Cambridge University Press.

Fletcher, Guy. 2013. 'A Fresh Start for the Objective-List Theory of Well-Being'. Utilitas 25: 206-220.

Frediani, Alexandre Apsan. 2007. "A Participatory Approach to Choosing Dimensions.” Maitreyee, E-bulletin of the HDCA 7: 6-10.

Goodin, Robert E. 1985. 'The Priority of Needs'. Philosophy and Phenomenological Research 45: 615-625.

Griffin, James. 1986. Well-Being: Its Meaning, Measurement, and Moral Importance. Oxford: Clarendon Press.

Grix, Marco, and Philip McKibbin. 2015. 'Needs and Well-Being'. In The Routledge Handbook of Philosophy of Well-Being, edited by Guy Fletcher, 292-306. Routledge.

Hooker, Brad. 2015. 'The Elements of Well-Being'. Journal of Practical Ethics 3: 15-35.

Maslow, A. H. 1943. 'A Theory of Human Motivation'. Psychological Review 50: 370-396.

Max-Neef, Manfred, Antonio Elizalde, and Martín Hopenhayn. 1989. 'Human Scale Development: An Option for the Future'. Development Dialogue 1: 7-80. 
Miller, David. 1979. Social Justice. Oxford: Clarendon Press.

1999. Principles of Social Justice. Cambridge, MA: Harvard University Press.

Nielsen, Lasse, and David V. Axelsen. 2017. 'Capabilitarian Sufficiency: Capabilities and Social Justice'. Journal of Human Development and Capabilities, 18: 46-59.

Nussbaum, Martha C. 2000. Women and Human Development: The Capabilities Approach. Cambridge: Cambridge University Press.

O’Neill, John. 2011. 'The Overshadowing of Needs'. In Sustainable Development: Capabilities, Needs, and Well-Being, edited by Felix Rauschmayer, Ines Omann, and Johannes Frühmann, 25-42. Abingdon: Routledge.

Qizilbash, Mozaffar. 1996. 'Capabilities, Well-Being and Human Development: A Survey'. The Journal of Development Studies 33: $143-162$.

1998. 'The Concept of Well-Being'. Economics and Philosophy 14: 51-73.

Rawls, John. 1982. 'Social Unity and Primary Goods'. In Utilitarianism and Beyond, edited by Amartya Sen and Bernard Williams, 159-185. Cambridge: Cambridge University Press.

Raz, Joseph. 1986. The Morality of Freedom. Oxford: Oxford University Press.

Reader, Soran. 2006. 'Does a Basic Needs Approach Need Capabilities?' Journal of Political Pbilosophy 14: 337-350.

Reader, Soran, and Gillian Brock. 2004. 'Needs, Moral Demands and Moral Theory'. Utilitas 16: 251-266.

Robeyns, Ingrid. 2017. Wellbeing, Freedom and Social Justice: The Capability Approach Re-Examined. Cambridge: Open Book Publishers.

Sen, Amartya. 1980. 'Equality of What?’ In Tanner Lectures on Human Values, 1: 197-220. Cambridge: Cambridge University Press.

1984. Resources, Values, and Development. Cambridge, MA: Harvard University Press.

1987. 'The Standard of Living: Lecture II, Lives and Capabilities'. In The Standard of Living, edited by Geoffrey Hawthorn, 20-38. Cambridge: Cambridge University Press.

1993. 'Capability and Well-Being'. In The Quality of Life, edited by Martha Nussbaum and Amartya Sen, 30-53.

Oxford: Oxford University Press.

1995. Inequality Reexamined. Oxford: Oxford University Press.

2004. 'Capabilities, Lists, and Public Reason: Continuing the Conversation'. Feminist Economics 10: 77-80.

2009. The Idea of Justice. Cambridge, MA: Harvard University Press.

Stewart, Frances. 1985. Basic Needs in Developing Countries. Baltimore, MD: Johns Hopkins University Press.

2006. 'Basic Needs Approach'. In The Elgar Companion to Development Studies, edited by David Clark, 14-18.

Cheltenham: Edward Elgar.

Streeten, Paul. 1979. 'Basic Needs: Premises and Promises'. Journal of Policy Modeling 1: 136-146.

1984. 'Basic Needs: Some Unsettled Questions'. World Development 12: 973-978.

Thomson, Garrett. 1987. Needs. London: Routledge \& Kegan Paul.

Wiggins, David. 1998. 'Claims of Need'. In Needs, V alues, Trutb: Essays in the Pbilosophy of V alue, 3rd ed., 1-57. Oxford: Oxford University Press.

2005. 'An Idea We Cannot Do Without: What Difference Will It Make (Eg. to Moral, Political and

Environmental Philosophy) to Recognize and Put to Use a Substantial Conception of Need?' The Philosophy of

Need, Royal Institute of Philosophy Supplement 57: 25-50.

Williams, Bernard. 1987. 'The Standard of Living: Interests and Capabilities'. In The Standard of Living, edited by Geoffrey Hawthorn, 94-102. Cambridge: Cambridge University Press.

Wolff, Jonathan, and Avner de-Shalit. 2007. Disadvantage. Oxford: Oxford University Press.

World Bank. 2017. Monitoring Global Poverty: Report of the Commission on Global Poverty. Washington, DC: World Bank Group. 